EVIDENCE BASED PUBLIC HEALTH POLICY AND PRACTICE

\title{
Economic efficiency of gatekeeping compared with fee for service plans: a Swiss example
}

\author{
Matthias Schwenkglenks, Georges Preiswerk, Roman Lehner, Fritz Weber, Thomas D Szucs
}

J Epidemiol Community Health 2006;60:24-30. doi: 10.1136/jech.2005.038240

See end of article for authors' affiliations

Correspondence to MrM Schwenkglenks, ECPM Research, c/o ECPM Executive Office, University Hospital, $\mathrm{CH}$ 4031 Basle, Switzerland; m.schwenkglenks@unibas. ch

Accepted for publication 1 September 2005

\begin{abstract}
Study objective: The impact of isolated gatekeeping on health care costs remains unclear. The aim of this study was to assess to what extent lower costs in a gatekeeping plan compared with a fee for service plan were attributable to more efficient resource management, or explained by risk selection.

Design: Year 2000 costs to the Swiss statutory sick funds and potentially relevant covariates were assessed retrospectively from beneficiaries participating in an observational study, their primary care physicians, and insurance companies. To adjust for case mix, two-part regression models of health care costs were fitted, consisting of logistic models of any costs occurring, and of generalised linear models of the amount of costs in persons with non-zero costs. Complementary data sources were used to identify selection effects.

Setting: A gatekeeping plan introduced in 1997 and a fee for service plan, in Aarau, Switzerland.

Participants: Of each plan, 905 randomly selected adult beneficiaries were invited. The overall participation rate was $39 \%$, but was unevenly distributed between plans.

Main results: The characteristics of gatekeeping and fee for service beneficiaries were largely similar. Unadjusted total costs per person were Sw fr231 (8\%) lower in the gatekeeping group. After multivariate adjustment, the estimated cost savings achieved by replacing fee for service based health insurance with gatekeeping in the source population amounted to Sw fr 403-517 (15\%-19\%) per person. Some selection effects were detected but did not substantially influence this result. An impact of non-detected selection effects cannot be ruled out.

Conclusions: This study hints at substantial cost savings through gatekeeping that are not attributable to mere risk selection.
\end{abstract}

$\mathrm{n}$ the early 1990s Switzerland was among the first European countries to introduce managed care solutions. ${ }^{1}$ Health insurance is mandatory in Switzerland and these solutions were offered to the population as an alternative to traditional fee for service plans. In 2001, managed care organisations had a market share of $5 \% .{ }^{2}$ Unlike in the USA, Swiss managed care lacks strong incentives to restrict the consumption of medical services. ${ }^{3}$

Early efforts to evaluate the medical and financial impact of managed care in Switzerland indicated reduced costs, but case mix adjustment was incomplete. ${ }^{5-7}$

Swiss gatekeeping plans report cost savings of $10 \%-25 \%$ compared with fee for service based health insurance. ${ }^{8}$ It remains unclear to what extent these savings are independent of risk selection mechanisms. Various studies have tried to answer similar questions for the USA and Europe, but findings were ambiguous. ${ }^{9-15}$

This study compares two local health plans, a gatekeeping and a fee for service plan, offered by the same group of health insurance companies in Aarau, Switzerland. These companies report costs to be about $10 \%$ lower in the gatekeeping plan, after adjusting for age and sex. We sought to assess to what extent this difference is attributable to more efficient resource management, or can be explained by risk selection.

\section{METHODS \\ Health plans}

In the region of Aarau, a group of four companies provides health insurance to about 31250 fee for service beneficiaries and 12500 gatekeeping beneficiaries. The terms of fee for service insurance are uniformly defined by Swiss law. Free access to primary care physicians and medical specialists is guaranteed. The gatekeeping plan is managed by a single intermediary company. Its beneficiaries pay reduced insurance premiums. They are required to choose a primary care physician who will also act as a care coordinator and help avoiding unnecessary use of medical resources such as duplicate diagnostic tests. Specialist visits, except in emergencies, require referral by that coordinating physician. However, there is direct access to ophthalmological and gynaecological care. General coverage of medical services does not differ between plans. Gatekeeping physicians have no financial incentives to limit the use of medical services. They receive a minor administrative fee of $\mathrm{Sw}$ frl2 per inscribed patient per year. Any additional time spent on their coordinating function is reimbursed at normal rates-that is, it is reflected in the gatekeeping beneficiaries' cost to the Swiss statutory sick funds. Gatekeeping physicians have varying proportions of fee for service patients.

\section{Study population}

The population studied were 18 years or older in 1996 and either fee for service or gatekeeping beneficiaries throughout 2000, whether they consumed medical services or not. (According to the intermediary company managing the gatekeeping plan, there were hardly any beneficiaries who switched between health plans during the year, except for persons who moved into or out of the area.) Cohorts of 905 beneficiaries of each plan were randomly selected from the enrolment files. In early 2001, they were mailed an informed consent form including a self administered questionnaire. Only beneficiaries returning the questionnaire became known to the investigators. Further data were provided on consenting participants by their insurance companies and physicians. Three weeks after the first letter was sent, nonresponders were mailed a reminder. Data collection was 
Table 1 Selected beneficiary characteristics by plan

\begin{tabular}{|c|c|c|c|}
\hline Characteristic & Gatekeeping $(n=433)^{*}$ & Fee for service $(n=267)^{*}$ & $\mathrm{p}$ Value \\
\hline Age (mean (SD) years) & $56.8(17.1)$ & $53.6(16.3)$ & $0.014 \pi$ \\
\hline Female (\%) & 53.2 & 60.3 & $0.068^{\star \star}$ \\
\hline Duration of health insurance with the same company (mean (SD) years) & $29.7(18.2)$ & $28.8(18.0)$ & $0.555^{\circ}$ \\
\hline Complementary insurance contracts (mean (SD) number) & $0.94(0.75)$ & $1.0(0.70)$ & 0.088 \\
\hline Importance assigned to low insurance premiums (mean (SD) score) $\dagger$ & $2.8(1.1)$ & $2.5(1.2)$ & $0.003+\dagger$ \\
\hline \multicolumn{4}{|l|}{ Professional status (\%)‡ } \\
\hline professionally active & 48.7 & 60.1 & $0.004^{* *}$ \\
\hline housework and childcare & 47.1 & 52.4 & $0.171^{\star *}$ \\
\hline unemployed & 1.9 & 2.6 & $0.492^{* *}$ \\
\hline retired & 41.6 & 32.2 & $0.013^{* *}$ \\
\hline \multicolumn{4}{|l|}{ Marital status (\%) } \\
\hline unmarried & 10.0 & 16.7 & $0.055^{\star *}$ \\
\hline married & 71.6 & 64.0 & \\
\hline widowed & 11.2 & 10.6 & \\
\hline divorced & 7.2 & 8.7 & \\
\hline \multicolumn{4}{|l|}{ Household size (mean (SD) number) } \\
\hline adults & $2.0(0.7)$ & $1.9(0.8)$ & $0.208+t$ \\
\hline children $\leqslant 18$ years & $0.40(0.82)$ & $0.35(0.73)$ & $0.631+\dagger$ \\
\hline Nursing home residency (\%) & 1.9 & 1.9 & $0.988^{* *}$ \\
\hline Residency in the Aarau area in 1996 (\%) & 97.2 & 90.6 & $<0.001^{* *}$ \\
\hline BMI (mean (SD) kg/m²) & $25.2(4.4)$ & $24.9(4.4)$ & $0.498^{\circ}$ \\
\hline Physically active or doing sports (\%) & 38.2 & 44.3 & $0.113^{* *}$ \\
\hline Current smoking (\%) & 22.2 & 30.0 & $0.022^{\star *}$ \\
\hline Current alcohol consumption & 87.0 & 87.2 & $0.801^{* *}$ \\
\hline Importance assigned to healthy nutrition (mean (SD) score) & $3.09(0.67)$ & $3.04(0.62)$ & $0.267 \dagger \dagger$ \\
\hline \multicolumn{4}{|l|}{ Subjective health status (mean (SD) score) } \\
\hline SF-36 general health scale & $70.6(18.5)$ & $71.3(19.9)$ & $0.648^{\circ}$ \\
\hline SF-36 physical health summary scale & $49.6(9.9)$ & $50.0(10.2)$ & 0.648 \\
\hline SF-36 mental health summary scale & $52.1(8.9)$ & $51.2(9.4)$ & 0.247 \\
\hline \multicolumn{4}{|l|}{ ICED (mean (SD) score) } \\
\hline in 2000 & $2.2(3.1)$ & $2.0(2.9)$ & $0.470+\dagger$ \\
\hline in 1996 & $1.8(2.7)$ & $1.5(2.4)$ & $0.378+\dagger$ \\
\hline History of mental illness (\%) & 17.1 & 18.8 & $0.635^{* *}$ \\
\hline
\end{tabular}

completed in June 2001. Elaborate procedures were applied to ensure a maximum of data protection.

\section{Study outcome and covariates}

The primary outcome was gross cost to the Swiss statutory sick funds in 2000. Collection of covariates aimed to permit comprehensive case mix adjustment. ${ }^{16}$ It included cost and morbidity data between January and December 1996, the year before the gatekeeping plan was first offered to the population. Cost data and health insurance contract details were provided by the insurance companies, the latter reflecting the beneficiaries' decisions taken in 1999 and defining their status in 2000. The physicians provided morbidity scores for 1996 and 2000 (index of co-existent diseases, ICED), ${ }^{17}$ physiological data, and their own practice characteristics. Data collection from the study participants comprised demographic and socioeconomic covariates; subjective health status (self administered SF-36); health behaviour; inclination to overuse or underuse medical services; and medical resource use. As discussed later, some of these covariates were time dependent and reported the situation at the time of data collection-that is, in the first half of 2001. Analyses were performed including and excluding these covariates.

In addition to the main dataset, anonymous age and sex data for all randomly selected potential participants and year 2000 cost data for the total source population, aggregated by age, sex, and health plan, were available. These were used to identify selection effects.

All costs are in Swiss francs ( Sw fr). On 31 December 2000, Sw frl equalled $€ 0.66$.

\section{Statistical methods}

Multiple logistic regression was used to model plan membership as a function of beneficiary characteristics identified in univariate analysis.

Table 2 Resource use and cost to the Swiss statutory sick funds by plan

\begin{tabular}{|c|c|c|c|}
\hline Characteristic & Gatekeeping $(n=433)^{*}$ & Fee for service $(n=267)^{*}$ & p Value $\S$ \\
\hline Primary care physician consultations in $2000 \dagger$ & $3.2(4.4) ; 2$ & $3.2(4.2) ; 2$ & 0.440 \\
\hline Medical specialist consultations in $2000+$ & $1.0(2.2) ; 0$ & $1.6(4.0) ; 0$ & 0.083 \\
\hline Hospitalisations in $2000+$ & $0.16(0.44) ; 0$ & $0.21(0.58) ; 0$ & 0.664 \\
\hline Total costs $>$ Sw frO in $2000(\%)$ & 83.6 & 83.6 & 0.984 \\
\hline Total costs in $2000 \ddagger$ & $2496(4870) ; 1120$ & $2727(4311) ; 1344$ & 0.407 \\
\hline Outpatient costs in $2000 \ddagger$ & 1815 (2287); 1102 & $2192(3113) ; 1261$ & 0.382 \\
\hline Inpatient costs in $2000 \ddagger$ & $680(3821) ; 0$ & $535(1948) ; 0$ & 0.994 \\
\hline Total costs $>$ Sw frO in $1996(\%)$ & 80.7 & 79.1 & 0.634 \\
\hline Total costs in $1996 \ddagger$ & $1674(2991) ; 731$ & $2436(5466) ; 824$ & 0.646 \\
\hline Outpatient costs in $1996 \ddagger$ & $1284(1702) ; 670$ & 1648 (2726); 811 & 0.469 \\
\hline Inpatient costs in $1996 \neq$ & 390 (1934); 0 & 789 (3849); 0 & 0.375 \\
\hline
\end{tabular}

*Number is smaller at the individual variable level because of missing values. †Mean number (SD); median. Self reported values, in good accordance with physician reported values. $¥$ Mean Sw fr (SD); median. Observations with zero values included. §Mann-Whitney U test. 


\begin{tabular}{|c|c|c|}
\hline$n=418^{*}$ & Log-likelihood $-99.05 \dagger$ & $\begin{array}{l}\text { Pseudo } r^{2} \text { of the } \\
\text { model }=0.43 \ddagger\end{array}$ \\
\hline Independent variable & Coeff $(95 \% \mathrm{Cl})$ & p Value \\
\hline $\begin{array}{l}\text { Fee for service plan membership } \\
\text { Fee for service plan membership divided by age } \\
\text { (women)§ }\end{array}$ & $\begin{array}{l}-3.43(-5.76 \text { to }-1.12) \\
138.51(35.37 \text { to } 241.65)\end{array}$ & $\begin{array}{l}0.004 \\
0.008\end{array}$ \\
\hline $\begin{array}{l}\text { Fee for service plan membership divided by age } \\
(m e n) \S\end{array}$ & $143.83(41.24$ to 246.42$)$ & 0.006 \\
\hline Age (women) & $0.01(-0.08$ to 0.11$)$ & 0.762 \\
\hline Age $^{2}$ (women) & $-0.001(-0.002$ to -0.000$)$ & 0.020 \\
\hline Age (men) & $-0.06(-0.12$ to -0.01$)$ & 0.021 \\
\hline 1996 outpatient costs (log scale) & $0.31(0.18$ to 0.43$)$ & $<0.001$ \\
\hline ICED score in 1996 & $0.67(0.12$ to 1.22$)$ & 0.017 \\
\hline ICED score increase between 1996 and 2000 & $0.73(0.14$ to 1.31$)$ & 0.016 \\
\hline SF-36 General Health Scale score & $-0.03(-0.06$ to -0.01$)$ & 0.018 \\
\hline \multicolumn{3}{|l|}{ Fixed beneficiary co-payment $\tau^{-}$} \\
\hline Sw fr 400 & $-0.85(-1.76$ to 0.06 & 0.067 \\
\hline Sw fr600 & $-0.92(-2.23$ to 0.39$)$ & 0.171 \\
\hline$\geqslant S w$ frl 200 & $-1.92(-3.04$ to -0.79$)$ & 0.001 \\
\hline Importance assigned to low insurance premiums ${ }^{\star *}$ & $0.41(0.07$ to 0.75$)$ & 0.019 \\
\hline Self reported low aversion of consulting a doctor ${ }^{* *}$ & $-0.43(-0.81$ to -0.06$)$ & 0.024 \\
\hline Being retired & $1.75(0.35$ to 3.14$)$ & 0.014 \\
\hline Constant & $5.42(1.96$ to 8.89$)$ & 0.002 \\
\hline
\end{tabular}

Expectedly, health care costs included a substantial proportion of zero values and were heavily left skewed and heteroskedastic (their variance increasing with increasing cost). Two-part regression models of total and outpatient costs were fitted. In the first part we modelled whether any costs were accrued using logistic regression and in the second, generalised linear models (GLMs) were used to analyse the amount of costs in the persons with non-zero costs. $^{18} 19$ The GLMs used a logarithmic link function and assumed a $\gamma$ distribution of errors. ${ }^{20}{ }^{21}$ Potential covariates were assessed if an association with costs seemed plausible on logical or on statistical grounds $(p \leqslant 0.25$ in univariate analysis). Firstly, all time dependent covariates primarily describing the situation in 2000 or 2001 were excluded (reduced models). In a second step (extended models), such covariates were permitted. Resource use variables were not used as covariates. As detailed in tables 4 and 5, some few observations with costs over Sw fr20 000 in 2000 were excluded from the main analysis, to reduce the impact of chance effects in this small sample. Complementary analyses included all available observations.

Total predicted values were calculated by multiplying the predicted values of both sub-models. ${ }^{21}$ To estimate the marginal (population level) cost impact of gatekeeping, all participants were assumed to be gatekeeping beneficiaries, or fee for service beneficiaries. Both sets of predicted values were calculated and their difference was taken. The result estimates the cost impact of replacing fee for service based health insurance with gatekeeping in the source population.

Two sided $p$ values of 0.05 were used to determine significance. Confidence intervals (CIs) shown are at the 95\% level. CIs for the marginal effects were calculated by bias corrected bootstrapping using 1000 repetitions.

\section{RESULTS}

\section{Participation and data availability}

In total, 700 (39\%) of the randomly selected persons returned the mailed questionnaire, $433(48 \%)$ of the gatekeeping beneficiaries and 267 (30\%) of the fee for service beneficiaries. In both groups, $86 \%$ of these consented to have additional data collected from their insurance companies and physicians. Full data inclusive of year 2000 cost data and year 1996 cost and morbidity data were finally available from 466 $(26 \%)$ of the randomly selected persons, 317 (35\%) of the gatekeeping beneficiaries and 149 (16\%) of the fee for service beneficiaries.

Data completeness among respondents was at least $90 \%$. Data provided by a total of 82 participating physicians were near complete, but some physicians who only treated fee for service beneficiaries refused to participate, which reduced the number of fee for service beneficiaries with full data available. Data provided by the insurance companies were complete.

\section{Beneficiary characteristics and health status}

Demographic characteristics, health insurance contract details, and indicators of socioeconomic status were similar between plans (table 1 ). The age range was $23-92$ years in the gatekeeping group and 23-96 years in the fee for service group. However, the gatekeeping beneficiaries were on average 3.2 years older than the fee for service beneficiaries and the proportion of women was lower by $7 \%$. The gatekeeping beneficiaries seemed to be slightly less mobile, less professionally active, and had a lower household income.

Both groups were similar with respect to health behaviour and health status (table 1). However, the gatekeeping group had a lower proportion of current smokers, especially in the younger age groups. The proportion of physically active persons was higher in the fee for service group (nonsignificant).

\section{Medical resource use and cost}

Table 2 details medical resource use and cost to the Swiss statutory sick funds. Fewer consultations with medical specialists and fewer hospitalisations were reported in the gatekeeping group and their year 2000 total costs per person were Sw fr231 lower. Outpatient costs were Sw fr377 lower (consultation costs, Sw fr7 lower; medication costs, Sw fr130 lower; other outpatient costs Sw fr239 lower). Inpatient costs were Sw frl45 higher in the gatekeeping group, but this difference was annulled when nine observations with costs over Sw fr20 000 were excluded. Year 1996 costs were Sw 
Table 4 Generalised linear model of total health care costs in 2000, per person with non-zero costs* (part 2 of two part model)

\begin{tabular}{|c|c|c|}
\hline Number $=347$ & Log-likelihood -2988.97 & Deviance 249.15 \\
\hline Independent variable & Coeff $(95 \% \mathrm{Cl})$ & $\mathrm{p}$ Value \\
\hline Fee for service plan membership & 0.24 (0.04 to 0.44$)$ & 0.021 \\
\hline Age (women) & $-0.03(-0.09$ to 0.02$)$ & 0.246 \\
\hline Age $^{2}$ (women) & 0.001 (0.000 to 0.001$)$ & 0.007 \\
\hline Age (men) & $-0.13(-0.21$ to -0.04$)$ & 0.003 \\
\hline $\mathrm{Age}^{2}$ (men) & $0.003(0.001$ to 0.005$)$ & 0.002 \\
\hline $\mathrm{Age}^{3}$ (women) & $-0.000(-0.000$ to -0.000$)$ & 0.007 \\
\hline 1996 outpatient costs (log scale) & $0.06(0.01$ to 0.10$)$ & 0.010 \\
\hline ICED score in 1996 & 0.61 (0.28 to 0.94 ) & $<0.001$ \\
\hline ICED score in 1996 * age (female) † & $-0.01(-0.01$ to -0.00$)$ & $<0.001$ \\
\hline ICED score in $1996 *$ age (male)t & $-0.01(-0.01$ to -0.00$)$ & $<0.001$ \\
\hline ICED score in $1996 * \mathrm{SF}-36$ Item $2 \dagger$ & $-0.07(-0.12$ to -0.01$)$ & 0.025 \\
\hline $\begin{array}{l}\text { ICED score in } 1996 * 1996 \text { outpatient costs (log } \\
\text { scale)† }\end{array}$ & $0.02(0.00$ to 0.05$)$ & 0.040 \\
\hline ICED score increase between 1996 and 2000 & $0.13(0.06$ to 0.20$)$ & 0.001 \\
\hline SF-36 Item 2 & $-0.13(-0.29$ to 0.03$)$ & 0.121 \\
\hline SF-36 General Health Scale score & $-0.01(-0.02$ to -0.01$)$ & $<0.001$ \\
\hline Complementary semi-private insurance & $-0.29(-0.50$ to -0.09$)$ & 0.005 \\
\hline Importance assigned to low insurance premiums & $0.10(0.02$ to 0.19$)$ & 0.017 \\
\hline Living in a partnership & 0.60 (0.19 to 1.01$)$ & 0.004 \\
\hline \multicolumn{3}{|l|}{ Marital status } \\
\hline married§ & $0.27(-0.15$ to 0.68$)$ & 0.208 \\
\hline widowed§ & $0.00(-0.48$ to 0.49$)$ & 0.989 \\
\hline divorced§ & $-0.63(-1.16$ to -0.10$)$ & 0.19 \\
\hline \multicolumn{3}{|l|}{ Household size } \\
\hline 2 adults $\uparrow$ & $-1.25(-1.67$ to -0.82$)$ & $<0.001$ \\
\hline$\geqslant 2$ adults $\uparrow$ & $-1.39(-1.88$ to -0.90$)$ & $<0.001$ \\
\hline \multicolumn{3}{|l|}{ Integration } \\
\hline Swiss born or Swiss citizen ${ }^{\star *}$ & $-0.39(-0.88$ to 0.11$)$ & 0.127 \\
\hline Swiss born and Swiss citizen** & $0.11(-0.33$ to 0.54$)$ & 0.624 \\
\hline Aarau area residency in 1996 & 2.04 (1.14 to 2.95$)$ & $<0.001$ \\
\hline Aarau area residency in $1996 *$ age (female) $\dagger$ & $-0.02(-0.05$ to 0.00$)$ & 0.069 \\
\hline Constant & 7.36 (5.69 to 9.03$)$ & $<0.001$ \\
\hline \multicolumn{3}{|c|}{$\begin{array}{l}{ }^{*} \text { Three gatekeeping observations and four fee for service observations with health care costs over Sw fr } 20000 \text { in } \\
2000 \text { not used. TTerm representing effect modification. } ¥ \text { Per increase by } 1 \text { on a } 5 \text { point Likert scale. } \$ \text { Compared } \\
\text { with unmarried. Combined likelihood ratio test, } p=0.054 \text {. } \uparrow \text { Compared with one adult. }{ }^{* *} \text { Compared with neither } \\
\text { Swiss born nor Swiss citizen. Combined likelihood ratio test, } p=0.034 \text {. }\end{array}$} \\
\hline
\end{tabular}

fr762 lower in the gatekeeping group, but this difference was reduced to Sw frl99 when six observations with costs over Sw fr20 000 were excluded. None of the differences observed were statistically significant.

\section{Complementary data sources}

Comparison with complementary data sources was undertaken to identify selection effects. Among all randomly selected persons, the observation of a higher mean age and a lower proportion of women on the gatekeeping side was confirmed, but less distinct. Participation rates by age and sex group showed moderate deviations $(1 \%-17 \%)$ from mean plan specific participation rates.

After adjusting for resulting differences in the age and gender distribution and after excluding all cases with costs over Sw fr20 000, year 2000 study level costs and the corresponding aggregated costs for the source population were similar. In the gatekeeping plan, study level total costs per person were Sw fr86 lower than population level costs, and in the fee for service plan, they were Sw fr69 lower. Within the strata defined by an age cut off of 65 years and sex, some of the differences seen were more distinct, but still

Table 5 Estimated cost impact of gatekeeping plan membership compared with fee for service plan membership (based on two part models)

\begin{tabular}{|c|c|c|c|c|c|}
\hline & Number* & $\begin{array}{l}\text { Cost difference (fee for service } \\
\text { minus gatekeeping) in persons } \\
\text { with non-zero costs } \ddagger\end{array}$ & Number† & $\begin{array}{l}\text { Cost difference (fee for service } \\
\text { minus gatekeeping) in all } \\
\text { persons§ }\end{array}$ & $\begin{array}{l}\text { Cost difference (fee for service } \\
\text { minus gatekeeping) in all } \\
\text { persons }(\%) \S థ\end{array}$ \\
\hline \multicolumn{6}{|l|}{ Total costs } \\
\hline Reduced model & 372 & 498 (-77 to 1072$)$ & 439 & $403(-120$ to 1027$)$ & 14.5 \\
\hline Extended model & 347 & 513 (53 to 973 ) & 395 & $517(-11$ to 1254$)$ & 18.9 \\
\hline \multicolumn{6}{|l|}{ Outpatient costs } \\
\hline Reduced model & 377 & 544 (76 to 1014$)$ & 444 & 453 (28 to 973 ) & 24.6 \\
\hline Extended model & 354 & 394 (23 to 765$)$ & 402 & $372(-4$ to 813$)$ & 17.9 \\
\hline
\end{tabular}

*Number available for GLM fitting. Reduced and extended total cost models, three gatekeeping observations and four fee for service observations with health care costs over Sw fr 20000 in 2000 not used. Reduced outpatient cost model, one fee for service observation with outpatient costs over Sw fr20000 in 2000 not used. In the extended outpatient cost model, this observation was not contained because of a missing value in one of the additional predictor variables. + Number available for estimation of marginal (population) effects. ‡Conditional effect in persons with non-zero costs as derived from GLM coefficients. Mean Sw fr per person (CI). $\S$ Marginal (population) effect (combined effect estimate of two part regression, comparing the assumptions of exclusive gatekeeping plan membership and with exclusive fee for service plan membership). Mean Sw fr per person (bootstrapped CI). $\bullet$ Expressed as a percentage of the costs incurred by the fee for service source population in the year of reference. 
moderate. The female fee for service beneficiaries above 65 years of age were the only exception. Their study level total costs were Sw fr740 lower than in the source population, compared with Sw fr8 lower in the corresponding gatekeeping beneficiaries.

\section{Predictors of plan membership}

Logistic regression indicated that gatekeeping plan membership in 2000 was positively associated with lower 1996 total health care costs; higher 1996 ICED score; having complementary dental insurance; having a higher importance assigned to healthy nutrition; having a lower household income; having more children in the household; living in the Aarau area in 1996; and having a primary care physician with a higher number of consultations per year. The explanatory power of the model remained low (pseudo $r^{2} 0.10,71 \%$ correct predictions).

\section{Predictors of cost}

In the reduced model, non-zero total costs in 2000 were associated with higher 1996 outpatient costs; higher 1996 ICED score; lower age (note: after correction for morbidity). The effect of plan membership was modified by age, hinting at a reduced probability of non-zero costs in younger gatekeeping beneficiaries and vice versa. Table 3 shows the extended model.

In the study of participants with non-zero costs, the reduced GLM showed higher total costs to be significantly associated with fee for service plan membership (likelihood ratio test, borderline $\mathrm{p}=0.066$ ); higher 1996 outpatient costs; higher 1996 ICED score; higher age; choice of lower selfpayments but higher insurance premiums; having complementary semi-private insurance; living in the Aarau area in 1996 (modified by age in women). The effect of 1996 ICED score was modified by age and 1996 outpatient costs. Table 4 shows the extended model.

Comparison of predicted and observed costs per person showed an overestimation in the fee for service group (difference Sw fr283 when regarding the extended total cost model), but not in the gatekeeping group (difference $\mathrm{Sw}$ $\mathrm{fr}-5$ ). When the female fee for service beneficiaries above 65 years of age (17 observations) were excluded, the difference seen in the fee for service group was reduced to $\mathrm{Sw}$ fr -86 .

\section{Association of gatekeeping and cost}

Direct parameter estimates derived from the conditional cost models as well as the estimated marginal (population) effects, comparing exclusive gatekeeping plan membership with exclusive fee for service plan membership, showed costs savings through gatekeeping at the total and outpatient levels (table 5). Estimated savings per person were in the range of Sw fr403-517 (15\%-25\% of the costs incurred by the fee for service source population). Some of the bootstrap based confidence intervals for the marginal effects overlapped the

\section{What this paper adds}

- The aim of gatekeeping is to reduce the cost of health care without affecting its quality, primarily by avoiding duplicate diagnostic tests and unnecessary consultations with specialists.

- Studies of the impact of gatekeeping in mixed settings, where other techniques of utilisation management were also in place, have been inconclusive. According to this study, isolated gatekeeping may be an efficient technique of utilisation management. null, but there was a strong and uniform tendency towards savings by gatekeeping. The reduced and extended models yielded consistent results at the total costs level, but the effect estimate derived from the reduced outpatient cost model seemed high.

Re-fitting the models and recalculating the marginal effects after inclusion of up to seven observations with costs over Sw fr20 000 led to higher effect estimates (for example, Sw fr773 instead of Sw fr517 when using the extended total cost model). In contrast, decreasing the cut off point further to $\mathrm{Sw}$ fr 15000 changed the effect estimates only marginally (Sw fr486 instead of Sw fr517). Exclusion of the female fee for service beneficiaries above 65 years of age yielded higher effect estimates ( $\mathrm{Sw}$ fr645 instead of $\mathrm{Sw}$ fr517). Exclusion of the persons who joined the gatekeeping plan later than in 1997 yielded results in the range of the main results ( $\mathrm{SW}_{w}$ fr481 instead of Sw fr517).

\section{DISCUSSION}

This study of a gatekeeping and a fee for service plan in Aarau, Switzerland, hints at relevant cost savings through gatekeeping that are not attributable to mere risk selection. Adjustment for case mix was achieved by performing two part multivariate analyses of year 2000 costs to the Swiss statutory sick funds, taking into account a wide variety of beneficiary and physician characteristics. The characteristics of gatekeeping beneficiaries and fee for service beneficiaries were largely similar. A considerable difference in the proportion of current smokers was concentrated on the younger study participants where a substantial impact on health care costs would not yet be expected. Whether physicians treated fee for service beneficiaries only, or beneficiaries from both plans, was not a significant predictor of cost on the fee for service side.

The result of case mix adjusted gatekeeping associated savings of around $20 \%$ confirms earlier Swiss reports and earlier, mostly trial based findings from the USA that gatekeeping may be an efficient technique of utilisation management. ${ }^{9-11} 22-24$ However, non-randomised US studies found no or only marginal costs savings associated with gatekeeping. ${ }^{13}{ }^{14} 25-27$ A European study using country level aggregate data found no gatekeeping effect on total costs, but significant savings in the outpatient setting. ${ }^{15}$

In this study, constraints on planned sample size in conjunction with a low response rate and incomplete information from some participants led to a small number of usable observations. Thus, the power to detect differential plan member characteristics may have been limited. Furthermore, response rates differed considerably between plans, hinting at the possibility of selection bias.

Accounting for a wide range of potential confounders reduced the probability of strong selection bias. Moreover, external data allowed us to assess in part to what extent selection effects were present in the study dataset. Essentially, comparison with aggregated cost data for the source population showed that this study found low costs in the female fee for service beneficiaries from age 65 onwards.

Comparison of predicted and observed costs at the GLM level showed an isolated over-estimation of costs in the fee for service group, implying a possible exaggeration of the gatekeeping effect. Exclusion of the observations representing female fee for service beneficiaries from age 65 onwards diluted this over-estimation. Re-estimation of the two part cost models after exclusion of this same group of observations did not reduce the combined estimates of the gatekeeping effect. This latter finding may suggest that the identified deviation of observed costs from population level costs at the subgroup level induced no strong distortion of the main study results. However, additional influences of 


\section{Policy implications}

Policy decisions that have an impact on national reimbursement systems, or on the type of products offered by health insurers, should consider gatekeeping as an option that avoids strong incentives to restrict the use of medical services and that may, therefore, be largely uncontroversial for a public concerned with quality.

non-detected selection effects alongside unmeasured covariates cannot be ruled out.

Cost and morbidity data for 1996, the year before the gatekeeping plan was first offered to the population, defined a baseline that could not be influenced by plan specific mechanisms.

The finding of cost savings through gatekeeping is not invalidated by the observation that the unadjusted increase in total health care costs between 1996 and 2000 was more pronounced on the gatekeeping side. As confirmed by logistic regression modelling of plan membership, persons with higher health care costs in 1996 but not persons with a higher 1996 ICED score were reluctant to join the gatekeeping plan. This must have led to a regression to the mean effect as it has been described before for similar settings. ${ }^{7} \mathrm{~A}$ higher mean age in the gatekeeping group and the fact that more persons in this group reached the age threshold of 65 years between 1996 and 2000 may also have contributed to the more pronounced increase seen here.

Data collection from the study participants occurred in the first half of 2001 and some time dependent covariates (describing subjective health status, health behaviour, and resource use preferences) reported the situation at this point in time, but were nevertheless used in the regression models on year 2000 costs. The intention was not to assess causeeffect relations between these covariates and the target variable, but merely to reduce the amount of unexplained variance and thus to achieve more precise estimates of the gatekeeping effect. Moreover, most of the covariates in question tend to change slowly over time. The differences between the health plans under study are fairly limited and unlikely to cause differential changes of attitudes, behaviours or even health status in the mid-term. Thus, the 2001 values of these covariates can be assumed to represent the situation directly before and in 2000 fairly adequately, except for random changes of health status.

All regression analyses on cost were performed excluding as well as including these covariates and the resulting estimates of the gatekeeping effect were similar. However, the reduced model on outpatient costs yielded effect estimates that were higher than those seen in the total costs. This was because of insufficient adjustment and it turned out that the difference in explanatory power between the reduced and extended models occurred mainly because no subjective health status variable was available for the former. The level of self payments chosen (an insurance contract detail) tended to be higher in healthier persons and could be used as an, albeit unsatisfactory, proxy. Variables indicating a high importance assigned to low insurance premiums, or a low household income, behaved near identical in all cost models, but the former was less affected by missing values and therefore preferred.

The gatekeeping plan under study does not incorporate additional utilisation management practices such as prospective utilisation review. ${ }^{28}$ It focuses on the avoidance of duplicate diagnostic tests and unnecessary specialist consultations. Some case management occurs informally. The exact mechanisms behind the cost savings seen could not be identified, as cost and resource use data were not detailed enough for a refined analysis of the medical services provided. Therefore, we cannot contribute to ongoing discussions whether the gatekeeping approach could be optimised, for example, by permitting direct specialist access for particular subgroups of persons or under special circumstances. ${ }^{29}{ }^{30}$ In our case, most savings were realised in the outpatient setting. The number of consultations was less important for the overall result than the amount of services performed per consultation and the amount of medications prescribed.

This study supports that utilisation management through gatekeeping may be associated with relevant savings in health care costs.

\section{ACKNOWLEDGEMENTS}

Beat Gasser, Atupri Krankenkasse, Berne; Asy Durrer, CONCORDIA Kranken- und Unfallversicherer, Lucerne; Dr René Kühne, Helsana Versicherungen AG, Zürich; Denise Fitzi, Winterthur Versicherungen, Winterthur; and Dr Arthur Vogt, Steinen, all Switzerland, contributed during preparation and conduction of the study. Dr Susan Ettner, UCLA Schools of Medicine and Public Health, Los Angeles, USA, and Professor Christoph Minder, ISPM, Berne, Switzerland, advised on statistical issues. Dr Adam Lowy, SIAK, Berne, Switzerland, and Professor Sebastian Schneeweiss, Boston, USA, made valuable comments on the manuscript.

\section{Authors' affiliations}

M Schwenkglenks, T D Szucs, European Centre of Pharmaceutical Medicine (ECPM), University of Basle, Basle, Switzerland G Preiswerk, SanaCare AG, Winterthur, Switzerland R Lehner, F Weber, Office based physicians, Aarau, Switzerland

Funding: this work was partially funded by unrestricted, educational grants from CONCORDIA Schweizerische Kranken- und Unfallversicherung, Lucerne; Helsana Versicherungen AG, Zürich; Krankenkasse SBB, Zürich; Wincare Versicherungen, Winterthur; Novartis Pharma Schweiz AG, Berne, all Switzerland.

Conflicts of interest: Georges Preiswerk is an employee of the company managing the gatekeeping plan under study. Roman Lehner and Fritz Weber are office based physicians treating beneficiaries of the health plans under study. Matthias Schwenkglenks and Thomas D Szucs: no potential conflicts of interest.

Ethical approval: On 27 February 2001, the data protection registrar of University Hospital, Zürich, Switzerland, the corresponding author's affiliation when this study was planned and data were collected, decided that an ethical approval was not required for this study as the design did not entail an intervention.

\section{REFERENCES}

1 Bohlert I, Adam I, Robra BP. [The Swiss gatekeeper system - a model for improving capacity development and economic effectiveness]. Gesundheitswesen 1997;59:488-94.

2 Anonymous. Managed-Care-Modelle in der Schweiz. Managed Care 2001;5:37-9.

3 Kuttner R. Must good HMOs go bad? First of two parts: the commercialization of prepaid group health care, N Engl J Med 1998;338:1558-63.

4 Baumberger J. So funktioniert Managed Care. Anspruch und Wirklichkeit der integrierten Gesundheitsversorgung in Europa. Stuttgart: Thieme, 2001:126-32.

5 Bundesamt für Sozialversicherung. Neue Formen der Krankenversicherung: Alters- und Kostenverteilungen im Vergleich zu der traditionellen Versicherung. Ergebnisse der Administrativdatenuntersuchung, 2. Teil. Bern Bundesamt für Sozialversicherung, 1998;11:136-41.

6 PROGNOS AG. Evaluation never Formen der Krankenversicherung. Synthesebericht. Bern: Bundesamt für Sozialversicherung, 1998:39-58.

7 Etter JF, Perneger TV. Health care expenditures after introduction of a gatekeeper and a global budget in a Swiss health insurance plan.J Epidemiol Community Health 1998;52:370-6.

8 Baumberger J. So funktioniert Managed Care. Anspruch und Wirklichkeit der integrierten Gesundheitsversorgung in Europa. Stuttgart: Thieme, 2001:136-7

9 Schillinger D, Bibbins-Domingo K, Vranizan K, et al. Effects of primary care coordination on public hospital patients. J Gen Intern Med 2000;15:329-36.

10 Martin DP, Diehr P, Price KF, et al. Effect of a gatekeeper plan on health services use and charges: a randomized trial. Am J Public Health 1989;79:1628-32. 
11 Galt KA, Rich EC, Kralewski JE, et al. Group practice strategies to manage pharmaceutical cost in an HMO network. Am J Manag Care 2001;7:1081-90.

12 Hurley RE, Freund DA, Gage BJ. Gatekeeper effects on patterns of physician use. J Fam Pract 1991;32:167-74.

13 Bonham GS, Barber GM. Use of health care before and during Citicare. Med Care 1987;25:111-19.

14 Vertrees JC, Manton KG, Mitchell KC. Case-mix adjusted analyses of service utilization for a Medicaid health insuring organization in Philadelphia. Med Care 1989:27:397-411.

15 Delnoij D, Van Merode G, Paulus A, et al. Does general practitioner gatekeeping curb health care expenditure? J Health Serv Res Policy 2000;5:22-6.

16 Schneeweiss S, Sangha O. [Provider profiling: needs, methodologic requirements and means to increase acceptance]. Dtsch Med Wochenschr $2001 ; 126: 918-24$

17 Greenfield S, Apolone G, McNeil BJ, et al. The importance of co-existent disease in the occurrence of postoperative complications and one-year recovery in patients undergoing total hip replacement. Comorbidity and outcomes after hip replacement. Med Care 1993;31:141-54.

18 Duan N, Manning WGJ, Morris CN, et al. A comparison of alternative models for the deman for medical care. Journal of Business and Economic Statistics 1983;1:115-26.

19 Mullahy J. Much ado about two: reconsidering retransformation and the two part model in health econometrics. J Health Econ 1998;17:247-81.
20 Diehr $\mathbf{P}$, Yanez D, Ash A, et al. Methods for analyzing health care utilization and costs. Annu Rev Public Health 1999;20:125-44.

21 Blough DK, Madden CW, Hornbrook MC. Modeling risk using generalized linear models. J Health Econ 1999;18:153-71

22 Huber-Stemich $F$, Hees K, Baumann $P$, et al. Sechs Jahre HMO ZürichWiedikon. Ein Erfahrungsbericht. Ars Medici 1996;18:1079-82.

23 Frey W. HMO- und Hausarztmodelle in der Schweiz. KSK aktuell. Konkordat der Schweizerischen Krankenversicherer 1996;4:54-5.

24 Manning WG, Leibowitz A, Goldberg GA, et al. A controlled trial of the effect of a prepaid group practice on use of services. N Engl J Med 1984;310:1505-10.

25 Hurley RE, Paul JE, Freund DA. Going into gatekeeping: an empirical assessment. QRB Qual Rev Bull 1989;15:306-14.

26 Long SH, Settle RF. An evaluation of Utah's primary care case management program for Medicaid recipients. Med Care 1988;26:1021-32.

27 Grembowski DE, Martin D, Diehr P, et al. Managed care, access to specialists, and outcomes among primary care patients with pain. Health Serv Res 2003;38: 1-19.

28 Wickizer TM, Lessler D. Utilization management: issues, effects, and future prospects. Annu Rev Public Health 2002;23:233-54.

29 Ferris TG, Chang Y, Blumenthal D, et al. Leaving gatekeeping behind-effects of opening access to specialists for adults in a health maintenance organization. N Engl J Med 2001;345:1312-17.

30 Escarce JJ, Kapur K, Joyce GF, et al. Medical care expenditures under gatekeeper and point-of-service arrangements. Health Serv Res 2001;36:1037-57.

\section{bmjupdates+}

bmiupdates+ is a unique and free alerting service, designed to keep you up to date with the medical literature that is truly important to your practice.

bmjupdates+ will alert you to important new research and will provide you with the best new evidence concerning important advances in health care, tailored to your medical interests and time demands.

Where does the information come from?

bmjupdates+ applies an expert critical appraisal filter to over 100 top medical journals A panel of over 2000 physicians find the few 'must read' studies for each area of clinical interest

Sign up to receive your tailored email alerts, searching access and more...

www.bmjupdates.com 